Goldberg's Genetic and Metabolic Eye Disease

Edited by William Andrew Rennie. (Pp 574; figures + tables. £72.90.) Boston: Little, Brown and Co. 1986.

The first edition of this book was published in 1974 and, since then, there has been an enormous increase in our knowledge of genetic eye disease, both in research and in clinical discoveries. Much of this increase has resulted from the development of recombinant DNA technology and its application to ophthalmology, and one of the new chapters in this second edition is devoted to this topic. The first third of the book is concerned with 'Methods of study in genetic eye disease' and the seven chapters in this section will give the ophthalmologist an up to date account of the fundamentals of modern clinical genetics.

The remaining 13 chapters are in a section entitled 'Genetic determination of clinical eye disease' and cover many aspects of ophthalmology. There are completely new chapters on strabismus and glaucoma, while those on corneal diseases, ectopia lentis, retinoblastoma, hereditary macular dystrophies, and oculocutaneous genetic diseases have been rewritten. The chapter on corneal diseases merits particular mention, as does that on hereditary macular dystrophies. The former contains an excellent, comprehensive, and succinct description of each corneal dystrophy, while the latter provides a valuable synopsis of this complex group of disorders.

This is a book that can be highly recommended to the practising ophthalmologist. The first section will bring him abreast of modern developments, while the second contains excellent vignettes on many aspects of genetic eye disease. The fact that it is not comprehensive does not detract from its value.

BARRIE JAY

\section{Human Prenatal Diagnosis}

Edited by K Filkins and J F Russo. (Pp 418; figures+tables. \$90.00.) New York: Marcell Dekker. 1985.

Medical geneticists usually regard prenatal diagnosis as their own subject. It has changed genetic counselling from a rather depressing cataloguing of risks into something with positive and hopeful options. Every advance in prenatal diagnostic technology has immediate impact in the counselling clinic. It has been instructive to watch the speed with which medical geneticists have mastered the complex language and concepts of molecular biology. They know that without this specialist knowledge their ability to counsel would quickly become dated.

It is therefore intriguing to encounter a book on prenatal diagnosis edited by two obstetricians, neither of whom I had encountered before. Karen Filkins contributes to a chapter on ultrasonography, but J F Russo is clearly weighed down by the scale of his editorial responsibility and keeps his writing pen sheathed. I have no idea what area of expertise he claims. But no matter. Perhaps by keeping some distance from the subject, the editors can bring a welcome detachment and balance to this rapidly changing subject.

It is very much an obstetrician's view of prenatal diagnosis. Indeed, and of some surprise to the geneticist, the longest chapter in the book covers ultrasonography in the third trimester. There are sections on fetoscopy, fetal echocardiography, chorionic villus sampling, embryoscopy, and fetal therapy, as well as on ultrasonography in the first and second trimesters. The chapter on the legal implications is cursory and ethical considerations are not discussed. I would have preferred more detail on the current position on the safety of chorionic villus sampling.

Perhaps inevitably, the book is at its weakest in its coverage of the laboratory based disciplines. The chapter on neural tube defects is particularly superficial, with acetylcholinesterase gaining a single footnote comment and lacking an index entry. Microvillar enzyme assay for cystic fibrosis is not mentioned. Although the section on inborn errors of metabolism has quite a comprehensive and useful table, prenatal diagnosis of Mendelian disorders by DNA analysis appears as an addendum. For a book with a publication date of 1985 , this suggests a lack of perspective on the cutting edge in prenatal diagnosis.

There has been a shortage in recent years of comprehensive textbooks on this subject. I doubt very much that this book by Filkins and Russo will fill the gap. It is poorly conceived, unattractively presented, and unnecessarily expensive.

D J H Brock

Oncogenes: Their Role in Normal and Malignant Growth

Edited by W F Bodmer, R Weiss, and J Wyke. (Pp $134 ; £ 15 \cdot 50$.) London: The Royal Society. 1985.

This is a slim volume which records the proceedings 
of a Royal Society discussion in December 1984. The foreword by the organisers of the meeting, W F Bodmer, $\mathrm{R}$ Weiss, and $\mathrm{J}$ Wyke, describes the meeting as "a series of vignettes that highlight current areas of growth of this fascinating topic". That is it, precisely. Each chapter is short, sometimes very short, and deals with a specific area ranging from insertional mutagenesis in murine mammary cancer ( $\mathrm{R}$ Nusse et al) through the identification of a nuclear location signal (a very neat observation by A E Smith $e t$ al), a substantial discussion by several groups of the c-myc gene, its product and its location, the role of oncogenes in cellular transformation (Marshall, Pragnell, and Beug), to the structure and function of epidermal growth factor receptor (Gullick et al). Although now nearly two years old (a long time in a fast moving field), I am confident that many will find this to be a very useful book; perhaps not those who are directly involved in this type of work but rather those who are on the periphery or perhaps in another field and who find the primary papers somewhat daunting. These short contributions, though quite detailed in some ways, are very readable and in many cases the main point being made shines through with great clarity because of the brevity. It should be made clear that the authors are not talking down to their readers in any way and maintain a very high level of scientific discussion. I would commend the book to anyone interested in the still growing field of oncogenes as a very useful guide to what has already been achieved, as well as to what can be done.

D G HARNDEN

\section{Genetics of Man}

By F Clarke Fraser and James J Nora. (Pp 352; figures + tables. \$34.00.) Philadelphia: Lea \& Febiger. 1986.

The dream of writing a book that becomes a best seller must be the real motivation for writing a basic medical or scientific textbook. The actual reality of attempting to write such a book must be like having a nightmare while awake.

The substantially revised second edition of this textbook covers the field of human and medical genetics and consists of a total of 24 chapters covering basic definitions, principles and practical examples of chromosomal, single gene, and multifactorial disorders, biochemical genetics, developmental genetics, immunogenetics, blood groups, population genetics, twins, somatic cell genetics, cancer, prenatal diagnosis, and genetic counselling. In addition there are useful and interesting chapters on topics such as race, dermatoglyphics, teratology. and syndromology which are not to be found many of the other basic textbooks in human or medical genetics.

In general the text is clearly laid out with mam headings, italicised subheadings, and key words $\overrightarrow{\text { or }}$ definitions in bold type in each chapter which make it easy to find particular topics in the text and wifP, along with summaries at the end of each chaptea, facilitate rapid revision for those facing the prospect of exams. The references at the end of each chapts for the reader wishing to pursue a particular topte further include selected classic papers, review aracles, or textbooks. The quality of the figures and tables is good and there is an interesting and adequate number of relevant clinical photographis. Specific criticisms of the presentation are that cross references could be used more liberally in the te?t and there are occasional instances where specifuc terms are used before they are defined.

The only criticism to be made of the book as $\bar{c}$ whole, as the authors admit in their preface to this edition, which is not necessarily a fault, is that the "may have yielded to the temptation to included more information than the average undergraduate may care to know about medical genetics". Many sections have detail to an extent appropriate to practising clinical geneticist but which, unfortonately, does not always illustrate basic underlying principles behind this practice and might result the loss of interest of undergraduates. It is therefoge difficult to know whether undergraduates, preclinical and clinical medical students, and 'paramedicals' would necessarily read this textbook as a whole or dip into it selectively.

Nevertheless this book more than adequated covers most aspects of human and medical geneties and is written in a straightforward, understandabite manner. It can be recommended as a basic textbogk which should be found useful by a wide range $\mathrm{g}^{\mathrm{f}}$ readers.

\section{R F Muell}

ก

\section{Human Growth: A Multidisciplinary Review} Edited by A Demirjan. (Pp 313; figures +tables. $£ 32 \cdot 00$.) London: Taylor and Francis. 1986.

The IVth International Congress of Auxology w held in Montreal in 1985. This book is the result of manuscripts submitted by the main speakers at the conference. In the words of the Editor, the Congress has assured the continuity of growth research to (?) create and define population specific standards, (b) investigate and understand the principal sources 